\title{
Intraoperative monitoring of the recurrent laryngeal nerve in surgeries for thyroid cancer: a review
}

\author{
SR Priya ${ }^{1,2}$, Srinjeeta Garg $^{3}$, Mitali Dandekar ${ }^{3}$ \\ ${ }^{1}$ Head Neck Surgery, Homi Bhabha Cancer Hospital and Research Centre, Visakhapatnam 530053, India. \\ ${ }^{2}$ Head Neck Surgical Oncology, Tata Memorial Centre, Mumbai 400012, India. \\ ${ }^{3}$ Head Neck Surgical Oncology, Paras Cancer Centre, Patna 800014, India.
}

Correspondence to: Dr. Mitali Dandekar, Head Neck Surgical Oncology, Paras Cancer Centre, Paras HMRI Hospital, Bailey Road, Patna 800014, India. E-mail: mitalidandekar@gmail.com

How to cite this article: Priya S, Garg S, Dandekar M. Intraoperative monitoring of the recurrent laryngeal nerve in surgeries for thyroid cancer: a review. J Cancer Metastasis Treat 2021;7:70. https://dx.doi.org/10.20517/2394-4722.2021.122

Received: 24 May 2021 First Decision: 19 Jul 2021 Revised: 26 Jul 2021 Accepted: 4 Aug 2021 Published: 17 Dec 2021

Academic Editors: Lucio Miele, Jerome M. Hershman Copy Editor: Yue-Yue Zhang Production Editor: Yue-Yue Zhang

\begin{abstract}
Intraoperative nerve monitoring (IONM) has evolved into an objective tool not only for the identification but also for the preservation and prognostication of function of the recurrent laryngeal nerve in thyroid surgeries. Technical improvements have resulted in the increasing incorporation of IONM into operating rooms around the world. The importance of adherence to recommended standards is also recognized as being vital in optimizing the efficacy of IONM. The advent of continuous IONM has made real-time nerve monitoring possible, thus providing the surgeon with an ally in difficult surgeries. Additionally, as thyroid surgeries are evolving into remote access and minimally invasive procedures, so also is the applicability of IONM. This review focuses on the use of IONM for nerve monitoring in thyroidectomies for neoplastic conditions while discussing the rationale, technique, and interpretation of findings and their implications.
\end{abstract}

Keywords: Intraoperative nerve monitoring, thyroidectomy, recurrent laryngeal nerve, electromyography, vagus nerve

\section{INTRODUCTION}

The incidence of total thyroidectomies performed for thyroid cancers in major centers across the globe has increased over the years, thus increasing the number of recurrent laryngeal nerves (RLN) at risk ${ }^{[1]}$. Injury to 
the RLN and consequent temporary or permanent palsy has significant implications on quality of life ${ }^{[2]}$. Patients at high risk for RLN palsy include those with thyroid malignancies, especially invasive thyroid cancers and bulky central compartment nodes ${ }^{[3]}$. Patients undergoing surgeries for recurrent disease and those undergoing completion surgery are also at a greater risk for RLN injury and permanent palsy ${ }^{[4]}$. Even though a number of palsies are temporary and many of these patients recover after a variable period ${ }^{[2,5,6]}$, any means of minimizing this risk should be considered crucial, considering the negative impact RLN injury has on quality of life with symptoms such as hoarseness, dysphagia, and stridor ${ }^{[7]}$. The morbidity is particularly severe when the palsy is bilateral ${ }^{[8]}$.

Intraoperative nerve monitoring (IONM) is emerging as one such tool that could be a means of reducing the incidence of this morbidity. While there can be no substitute for an inside-out familiarity with the anatomy of the thyroid gland or of experience in these procedures, the IONM is a corroborative method and useful adjunct for nerve identification, preservation, and prognostication of function in thyroid and parathyroid surgeries.

Subsequent to technological advances, IONM apparatuses are now more compact and easily incorporated into the operating room environment ${ }^{[9]}$. However, the essentialities such as system setup, anesthesia protocol modifications, and negotiation of the learning curve by the surgeon(s) as well the anesthetist(s) and neurophysiologist remain the same ${ }^{[10]}$.

\section{TYPES OF INJURIES TO THE RLN DURING THYROIDECTOMY}

Since the RLN lies in close approximation to the thyroid gland, a wide array of maneuvers can injure the RLN. However, only about $14 \%$ of these injuries are visible at the time of surgery ${ }^{[11]}$. Since cancer surgeries mandate the removal of entire thyroid tissue even from difficult areas, the RLN is particularly vulnerable at the ligament of Berry ${ }^{[12]}$. Fortunately, most of the RLN injuries are transient and recover within six months ${ }^{[6]}$.

RLN injury can be classified as follows:

1. Based on duration:

a. Transient

b. Permanent

The time duration for categorizing vocal cord palsy as permanent varies in different series, ranging from 3 to 12 months ${ }^{[13]}$.

2. Based on etiology:

a. Traction

b. Transection

c. Thermal (due to cauterization) 
d. Compression

e. Ligation

3. Based on the extent of injury:

a. Type I or segmental

b. Type II or global

Segmental or Type I injury is rapid in onset, more severe and slower to recover. It could be due to traction, cauterization, ligation, or compression around the nerve. Global or Type II injury is more gradual in onset, milder, and more likely to recover rapidly. It is usually due to traction ${ }^{[14]}$.

The vast majority (> 70\%) of nerve injuries are traction or stretch related. Majority of traction-related injuries are transient and most recover with time. Dionigi et al. ${ }^{[11]}$ reported that, of all etiologies resulting in RLN paralysis, thermal, clamping, and transection are the most severe resulting in permanent palsy in $28 \%$, $50 \%$, and $100 \%$ or patients, respectively.

\section{PHYSIOLOGY OF THE NERVE AND BASIS OF IONM}

RLN is a mixed motor and sensory nerve; the motor component supplies the intrinsic muscles of the larynx resulting in normal vocal cord movement. The nerve fibers when stimulated release a compound action potential (CAP), which is a sum of impulses of the nerve fibers. The CAP traverses through the nerve resulting in a waveform recordable by placing electrodes at muscle end plates. This is recorded as electromyography (EMG) potentials or compound muscle action potentials (CMAP). Thus, IONM is an EMG recording of $\mathrm{CMAP}^{[9]}$.

Intraoperatively, a neural insult results in ischemia of the vasa nervosum when more than $5 \%$ of the nerve is stretched, resulting in neuropraxia ${ }^{[9,15]}$. This progresses to reduction in recruitment of functional nerve fibers resulting in decrease in amplitude ${ }^{[16]}$. Further insult causes loss of myelin sheaths and axonotmesis resulting in an increase in latency ${ }^{[9]}$. More than 50\% reduction in amplitude and $10 \%$ increase in latency is considered significant with respect to loss of nerve function, especially if these combined events occur for $40 \mathrm{~s}$ or longer ${ }^{[17]}$. However, these events are reversible if the offending maneuver is altered (release of traction, etc.). Non-recovery of the amplitude within $20 \mathrm{~min}$, however, portends a high risk for postoperative vocal cord palsy $^{[18]}$.

Physiologically, Wallerian degeneration of the distal segment after the neural insult sets in $48-72 \mathrm{~h}^{[19]}$. Thus, the nerve segment distal to the site of injury continues to generate a response on stimulation intraoperatively ${ }^{[20]}$. This has implications on monitoring the post dissection response (R2), as described in subsequent sections.

\section{LEARNING CURVE}

While understanding neurophysiology is essential for interpretation of the findings of IONM, the experience of the operating team contributes to overcoming problem issues, thus helping identification of impending injuries and aiding crucial intraoperative decisions. This in turn has a bearing on patient counseling with regards the possibilities of change in operative plans. Most authors who have examined the 
learning curve for application of IONM in thyroidectomies agree that the utility of this tool is proportionate to the experience of the surgeon as well as the anesthetists. It has been estimated that a surgeon would require performing at least 50 consecutive cases with IONM over a 20-month period to gain proficiency in reducing technical errors and improving applicability ${ }^{[2,22]}$. Once issues related to lack of experience have been overcome, IONM has the ability to complement or even substitute the presence of an experienced guide during surgery ${ }^{[23]}$.

\section{METHODS AND TECHNIQUE}

Neurophysiological monitoring can be performed at the level of the brain, spinal cord, cranial nerves, and peripheral nerves. Some of the methods of evaluation include brainstem evoked potentials, triggered EMG, and free-running EMG. In free running EMG, responses are mechanically evoked EMGs measured as burst responses, train activity, and sounds such as the burst of popcorn, a dive bomber, machine gun ${ }^{[24]}$, etc. These responses are obtained even on minimal manipulation such as irrigation of the nerve ${ }^{[25]}$. Although it aids in monitoring during skull base surgeries ${ }^{[26]}$, it may not be optimal for monitoring the nerve during thyroid surgery where the nerve is in close approximation to the gland. Essentially, nerve integrity monitoring for peripheral nerves, particularly in thyroidectomy, assesses EMG on electrical stimulation with precisely recordable responses. It is performed either intermittently which is most widely used or continuous IONM (CIONM), which is rapidly evolving.

The technique described below is that of open thyroidectomy using a NIM3.0 Response monitoring system (Medtronic Xomed, Jacksonville, Flo, USA).

The setup involves completing a loop of circuits comprising the stimulation side and the recording side, which are connected at an interface. The interface is then connected to a monitor, which displays an auditory and visual response represented by waveforms of amplitude and latency.

The stimulation circuit comprises a monopolar or bipolar probe which transmits electrical impulses to the nerve and a Stim return electrode (grounding electrode). The recording side comprises the recording electrodes and a ground electrode [Figure $1 \mathrm{~A}$ and $\mathrm{B}$ ].

Traditionally, the recording electrodes were inserted onto the vocalis muscle either through the cricothyroid membrane or endoscopically. Other methods of assessment included laryngeal palpation or glottic pressure $^{[27]}$. This has largely been replaced by mounting the electrodes as surface electrodes on the endotracheal tube to make it less cumbersome ${ }^{[28-31]}$ [Figure 2].

The ground electrodes are inserted on a bony prominence in the vicinity of the operating field, the most suitable location being the sternum or, alternatively, the clavicle ${ }^{[2,33]}$. These electrodes are connected via the patient interface to the monitor which displays the waveforms. Once all the electrodes are in place, i.e., the surface recording electrodes and the Stim return and ground electrodes, they are verified by a system check on the monitor [Figure 3].

\section{Checklist to avoid technical errors during system setup}

Tube placement

The tube with mounted electrodes must fit snugly at the level of the vocal cords. Lubrication at the level of the electrodes must be avoided. In addition, neck extension after intubation could misplace the tube and hence tube position must be reconfirmed after the final positioning of the patient ${ }^{[34]}$. 

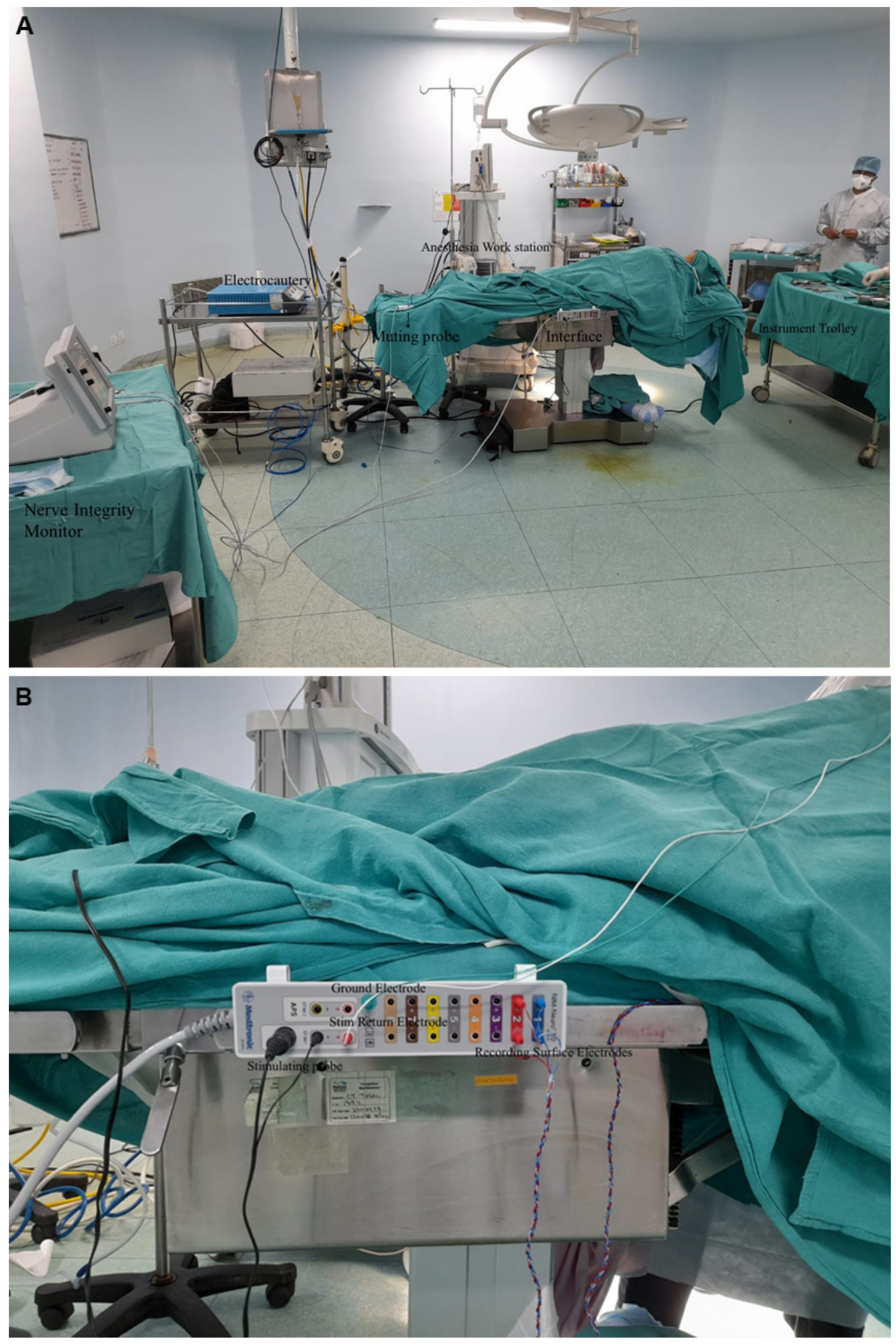

Figure 1. (A) Operating room set up for a thyroidectomy procedure with intraoperative nerve monitoring. (B) Interface between the stimulation side and recording side. 


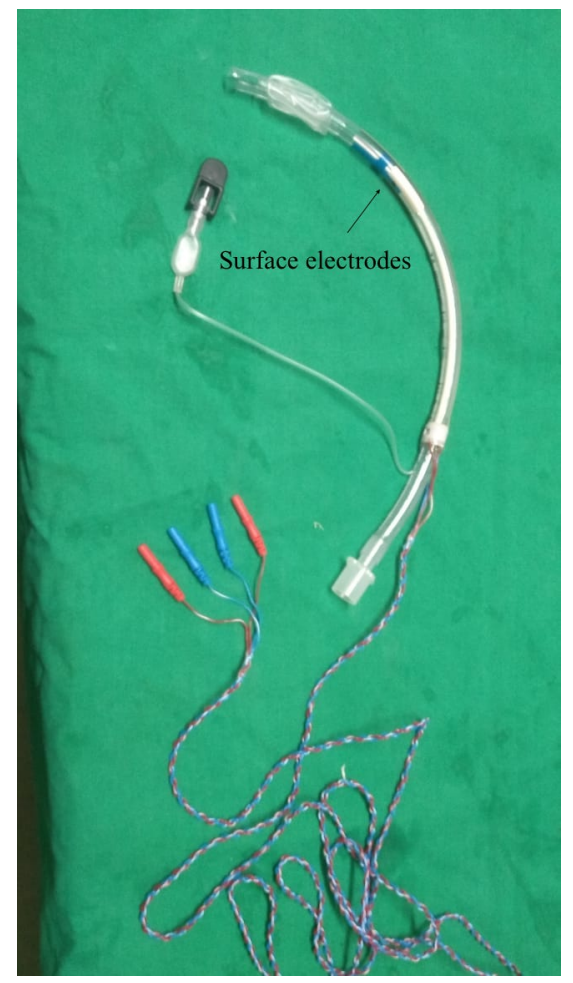

Figure 2. Endotracheal tube with surface electrodes.

\section{Anesthetic drugs}

Avoid muscle relaxants which interfere with CMAP for EMG reading. In addition, the anesthesiologist must ensure that the plane of anesthesia is deep enough to avoid spontaneous vocal cord movement, thus resulting in a disturbing tone due to constant fibrillations of the cords.

\section{Electrical/magnetic interference}

Ensure minimal interference from surrounding equipment by acquiring an independent electrical connection for the IONM as well as by using a muting probe on the electrocautery machine [Figure $1 \mathrm{~A}$ and $\mathrm{B}]$.

The circuit is verified by manually tapping the posterior cricoid to achieve a mechanically stimulated EMG response on the monitor ${ }^{[30]}$.

\section{Electrical settings}

The stimulating probe discharges electrical impulses which depolarize axons at the site of stimulation. The stimulation intensity is set at $1 \mathrm{~mA}$ and the amplitude threshold is set at $100 \mu \mathrm{V}^{[31]}$.

\section{Intraoperative steps}

Surgery can commence once the system has been set up as described above. After elevation of the subplatysmal flaps, ipsilateral sternomastoid muscle is retracted to expose the carotid sheath. The vagus nerve is either dissected or else mapped on the carotid sheath with the probe with $2 \mathrm{~mA}$ amplitude ${ }^{[34]}$. This is recorded as the pre-dissection vagal ( $\left.\mathrm{V}_{1}\right)$ signal. While dissecting the right sided nerve, it is advisable to stimulate the vagus at two points: one above the level of the cricoid and another lower down the neck. A positive signal higher up and a negative signal lower down must alert the surgeon of the possibility of a non- 


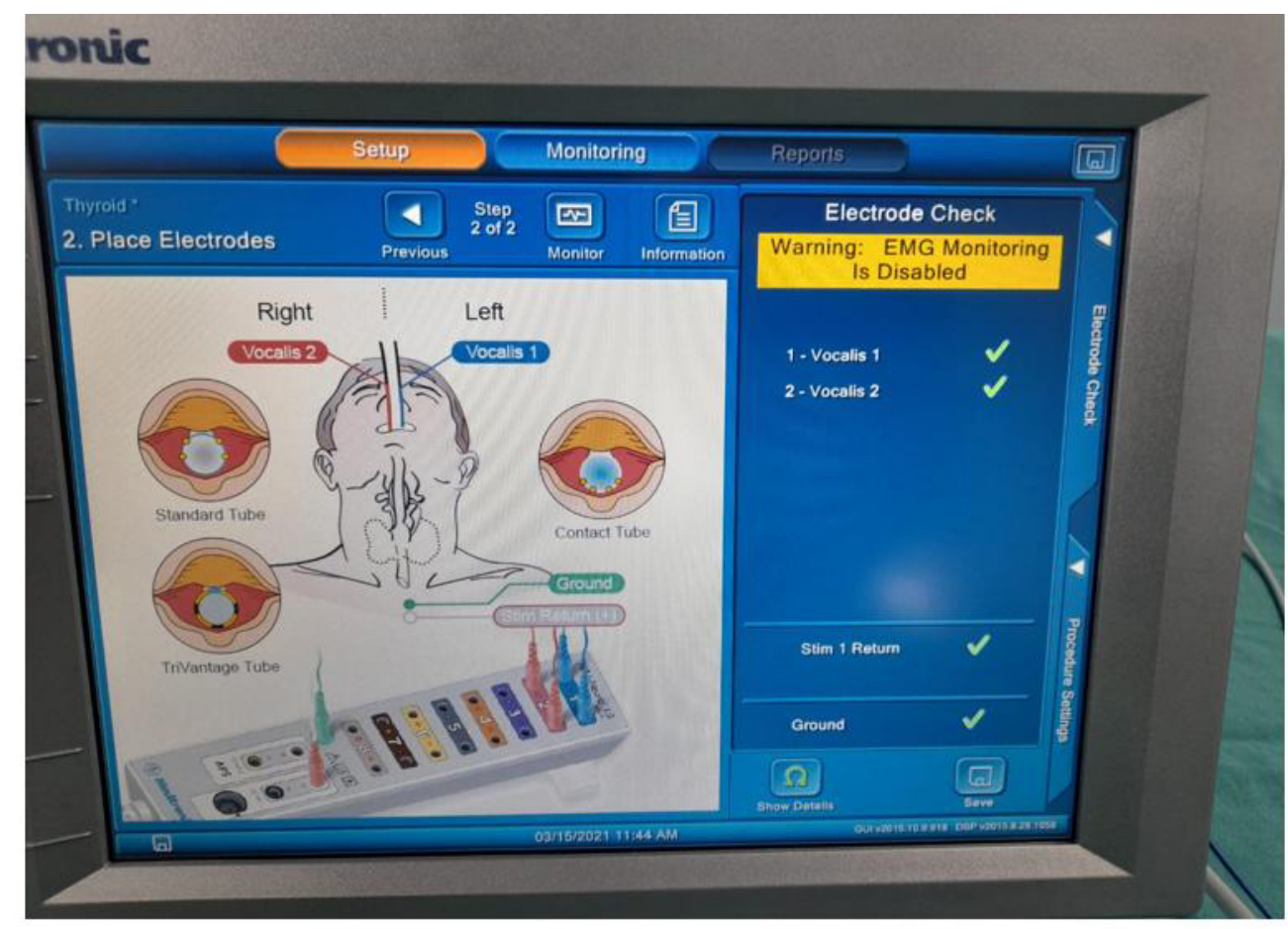

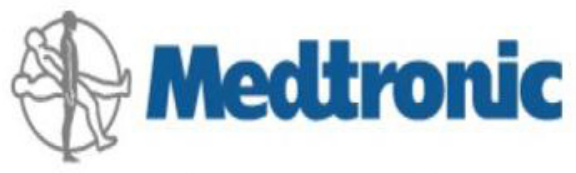

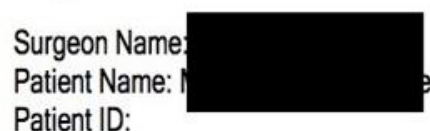

Patient ID:

Procedure: Thyroid

\section{NIM-Neuro@ 3.0 \\ GUI 2015. 10.9.918 DSP 2015.8.28.1058}

Report Created on: 03/15/2021 11:42 AM

Page 1

\begin{tabular}{|c|c|c|c|c|c|c|c|c|c|c|c|}
\hline \multicolumn{12}{|c|}{ Electrode Checks (kOhms) } \\
\hline & + & - & $\Delta$ & & + & $\cdot$ & $\Delta$ & & + & - & $\Delta$ \\
\hline \multicolumn{12}{|c|}{ 3/15/2021 11:42:51 AM } \\
\hline Vocalis 1 & 0.31 & $<0.1$ & 0.26 & Vocalis 2 & $<0.1$ & 0.12 & $<0.1$ & Stim1Return & 0.46 & & \\
\hline Stim2Return & OFF & & & Ground & 0.84 & & & & & & \\
\hline
\end{tabular}

Figure 3. Electrode check.

recurrent laryngeal nerve ${ }^{[35]}$. The surgery is further continued with retraction of the strap muscles and exposing the ipsilateral thyroid lobe. Dissection is continued with ligation of the superior pole. The first sight of the RLN either at the Beahr's or Lorre's triangle is confirmed with the monopolar probe, and the waveform is recorded as the pre-dissection nerve (R1) signal. Once thyroidectomy is completed, the RLN signal is again recorded as the post-dissection nerve (R2) signal. Here, stimulation of the most proximal part of the exposed nerve or the entire visible nerve is necessary to rule out any segmental nerve injury. After completion of hemostasis and approximation of the strap muscles, the vagus is stimulated to achieve Post dissection vagal (V2) signal ${ }^{[35]}$. The interpretation of the signals is tabulated in Table 1. 
Table 1. Interpretation of signals

\begin{tabular}{|c|c|c|c|}
\hline No. & Signal & Interpretation & Troubleshooting \\
\hline 1 & $\begin{array}{l}\text { No signal at } \\
\text { V1 }\end{array}$ & $\begin{array}{l}\text { - Equipment failure/technical error } \\
\text { - Absence of signal on stimulation at a single point on the right } \\
\text { side should alert the surgeon of the possibility of a non-recurrent } \\
\text { laryngeal nerve }\end{array}$ & $\begin{array}{l}\rightarrow \text { Manual palpation of posterior cricoid on stimulation } \\
\text { of vagus: twitch if present suggests recording side } \\
\text { issue } \\
\rightarrow \text { Stimulate the vagus at two points on the right side: } \\
\text { above the level of cricoid and lower down } \\
\text { Check: } \\
\text { - Endotracheal tube placement } \\
\text { - Salivary pooling } \\
\text { - Status of muscle relaxants }\end{array}$ \\
\hline 2 & $\begin{array}{l}\text { No signal at R1 } \\
\text { (with a normal } \\
\text { V1) }\end{array}$ & Nerve not correctly identified & $\begin{array}{l}\text { Rule out stimulation and recording side glitches which } \\
\text { may have occurred after V1 }\end{array}$ \\
\hline 3 & $\begin{array}{l}\text { Loss of signal } \\
\text { (LOS) at R2 } \\
\text { (with normal } \\
\text { V1 and R1) }\end{array}$ & Suggests nerve insult & $\begin{array}{l}\text { Check: } \\
\text { - Contralateral nerve stimulation: if present, rules out } \\
\text { technical glitches } \\
\text { - Manual stimulation of posterior cricoid: twitch if } \\
\text { present suggests recording side error }\end{array}$ \\
\hline 4 & LOS at V2 & $\begin{array}{l}\text { Rule out nerve insult not detected at R2 (when the distal segment } \\
\text { is stimulated) }\end{array}$ & $\begin{array}{l}\text { If LOS at R2 is true positive, rule out pressure over RLN } \\
\text { due to hematoma, collection, or during drain placement }\end{array}$ \\
\hline
\end{tabular}

An intact signal loop of V1-R1-R2-V2 ensures intactness of the nerve, and the contralateral lobe can be addressed if indicated.

One must be cautious of a normal signal response while eliciting R2 in the presence of nerve injury (false positive signal): this occurs in segmental (Type I) nerve injury when the nerve is stimulated distal to the site of injury. Hence, one must elicit R2 in the entire visible length of the nerve or the proximal most part of the visible nerve to achieve a genuine response.

CIONM: After raising the subplatysmal flaps, the carotid sheath is dissected to identify the vagus nerve. The nerve is completely released from the other structures at 360 degrees. An automatic periodic stimulation electrode is inserted hugging the vagus nerve after dissection of the carotid sheath ${ }^{[31]}$ [Figure 4]. This electrode delivers continuous low-level stimulation ${ }^{[32]}$. This electrode replaces the stimulating probe. The rest of the system setup is essentially similar to the intermittent IONM.

\section{READINGS}

\section{Normal readings}

The cardinal components of readings in an EMG waveform comprise amplitude and latency ${ }^{[36]}$. An unstimulated muscle does not produce any waveform. There could be non-specific baseline undulations that should be differentiated from evoked waveforms for the human RLN or vagus nerve, which are commonly biphasic or triphasic ${ }^{[37]}$.

The amplitude of a monitoring waveform, as defined in the international guidelines, is the vertical height of the apex of the positive initial waveform deflection to the lowest point in the subsequent opposite polarity phase of the waveform ${ }^{[31]}$.

Latency is taken at the time interval between the point of stimulation and the first peak point of the evoked potential (negative or positive) from the baseline ${ }^{[0,31]}$. 


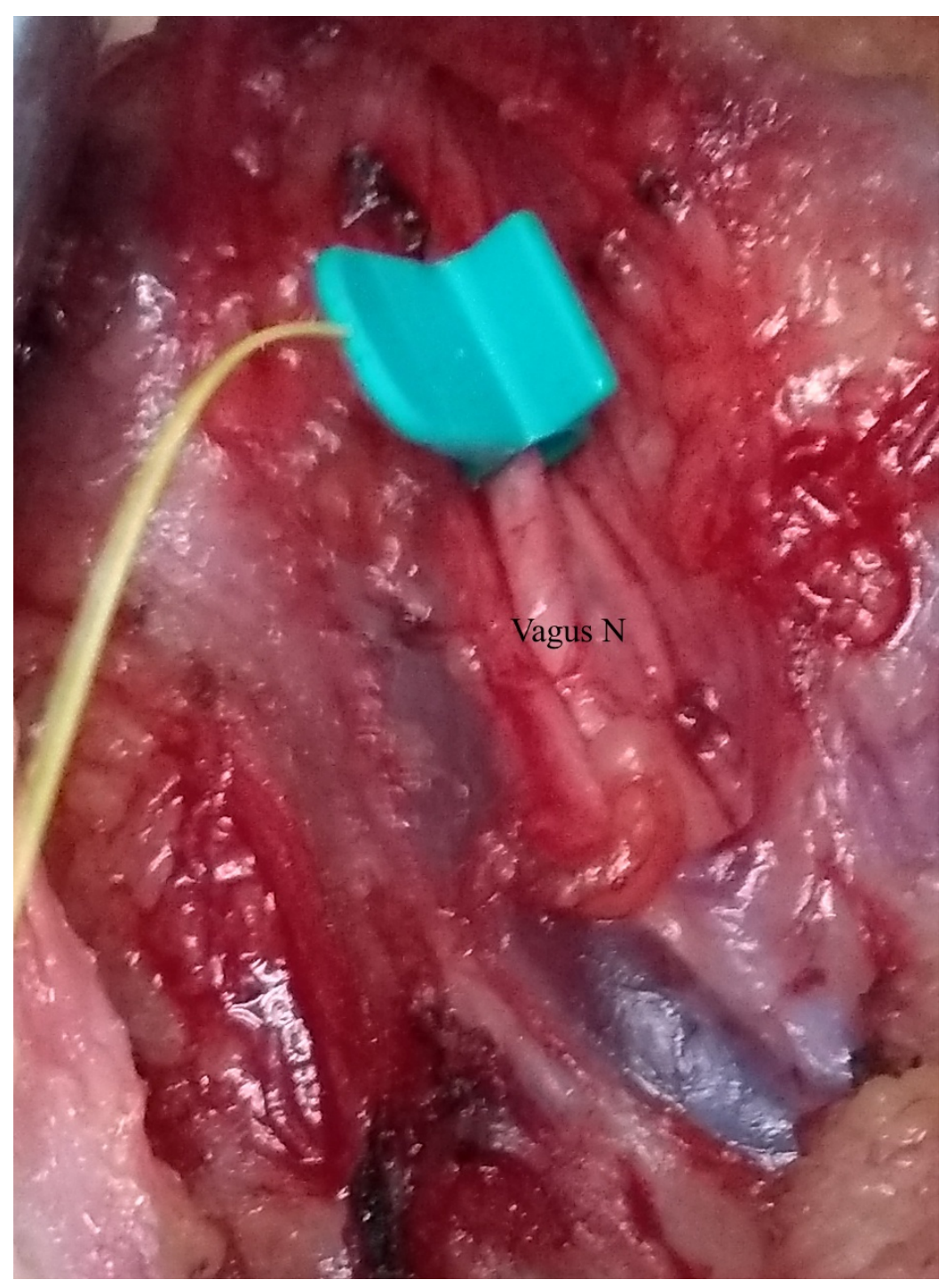

Figure 4. Automatic Periodic Stimulation (APS) electrode mounted around the vagus nerve.

Normative readings of the EMG on the RLN have been determined and can be employed as standards for comparison $^{[38-40]}$. An optimal IONM signal is a nerve amplitude of $\geq 500 \mu \mathrm{V}$ at baseline and with a stimulation intensity of 1-2 mA. Sritharan et al. ${ }^{[40]}$ found a mean amplitude of $739.7 \mathrm{mV}$ for the vagus nerve and $891.6 \mathrm{mV}$ for the RLN. An amplitude of $>250 \mu \mathrm{V}$ is highly predictive of a functioning RLN. This is particularly important while differentiating between preoperative and final postoperative evoked amplitudes at $1 \mathrm{~mA}$. It was found that the final amplitude at the end of dissection/end of surgery (R2) between 247 and $3607 \mu \mathrm{V}$ is associated with a functional $\mathrm{RLN}^{[4]}$.

Figure $5 \mathrm{~A}$ and $\mathrm{B}$ demonstrates readings of the RLN signal pre- and post-dissection suggesting normal functioning nerve.

Latency: In an optimal IONM signal, the expected latency from stimulation to achieving CMAP on the EMG is 3-3.5 ms. Latency, however, differs between the sides as well as the nerves. Potenza et al. ${ }^{[38]}$ found a median latency of $3.10 \mathrm{~ms}$ for the right RLN and $4.25 \mathrm{~ms}$ for the left RLN. The right vagus demonstrated a 


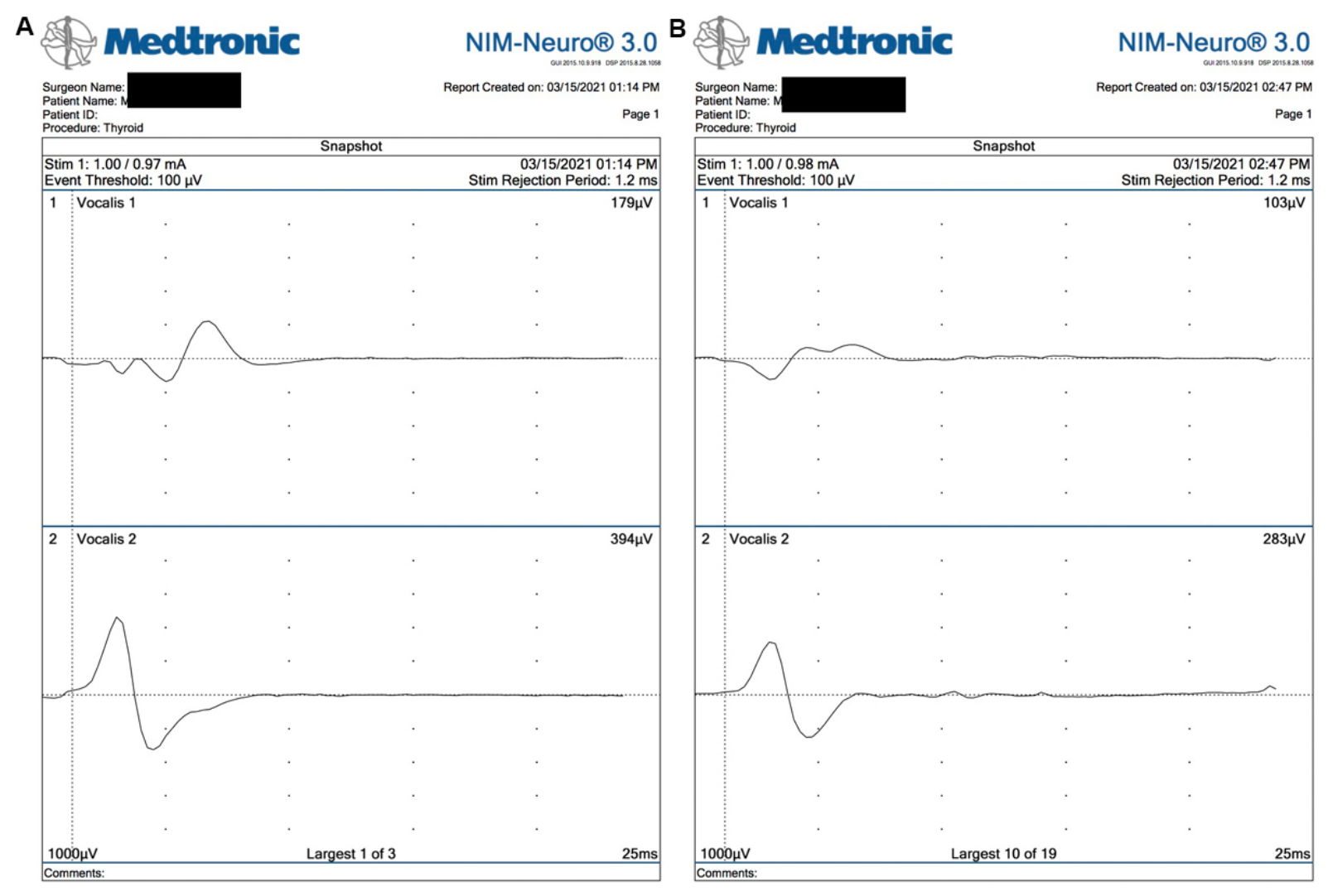

Figure 5. (A) Pre-dissection right-sided vocalis signal. (B) Post-dissection right-sided vocalis signal.

median latency of $6.47 \mathrm{~ms}$ and the left vagus had a median latency of $7.42 \mathrm{~ms}$. In another study, Sritharan et al..$^{[40]}$ found the mean latency of the left vagus to be $8.14 \mathrm{~ms}$ compared to a mean right vagal latency of $5.47 \mathrm{~ms}$. In the same series, the mean left RLN latency was $4.19 \mathrm{~ms}$, while the mean right RLN latency was $3.73 \mathrm{~ms}$.

\section{Abnormal readings and signs of impending or actual nerve injury}

An EMG is considered to be abnormal if either the amplitude or latency is affected; these changes may be isolated or combined. The latter, i.e., combined events, are seen to be more predictive of function loss ${ }^{[38]}$. This is because isolated abnormal readings of variable, amplitude or latency, could arise from technical glitches. Combined events could be mild or severe. Mild combined events are those where the amplitude decreases from $>50 \%$ to $70 \%$ with a concordant latency increase of 5\%-10\%. Severe combined events (sCEs) are those with reduction in the amplitude of $>70 \%$ with a latency increase of $>10 \%$. Phelan et al ${ }^{[17]}$ reported six cases that developed a temporary VCP, and, of those, $83 \%$ had developed intraoperative sCEs. Moreover, the average number of sCEs for group was 29. On the other hand, of the patients with a normal postoperative vocal cord examination, only $20 \%$ developed sCEs during surgery and, importantly, the average number of sCEs for this group was $3.5^{[17]}$.

When such combined events happen, it is crucial to release the nerve immediately by relaxing traction (the most common cause) and to wait until the nerve amplitude has regained $\geq 50 \%$ of its baseline. If these CEs recur repeatedly, the surgeon may consider changing their surgical strategy, e.g., a lateral approach as opposed to a midline approach. If the basic cause is not removable and the CE persist for $40 \mathrm{~s}$ or longer and if the initial injury was severe, the CEs may progress to "loss of signal" (LOS) ${ }^{[17,41]}$. 
LOS is defined as either complete loss of amplitude or decrease of the nerve amplitude to $100 \mu \mathrm{V}$ after suprathreshold stimulation (1-2 mA), paying careful attention to troubleshooting algorithms ${ }^{[31]}$.

Not all cases with LOS will have permanent RLN palsy. The literature suggests that recovery of amplitude to $50 \%$ of baseline amplitude always indicated normal early postoperative vocal fold function ${ }^{[40]}$. However, LOS is a grave finding, and, in this series, only $17 \%$ of those with LOS intraoperatively exhibited recovery ${ }^{[17]}$. LOS developing acutely was more likely to develop into nerve palsy as opposed to a gradually occurring $\operatorname{LOS}^{[42]}$. LOS, if transient, generally recovers within 20 min of occurrence ${ }^{[18,21]}$.

\section{MANAGEMENT DECISIONS AFTER TRUE LOS}

True LOS could suggest either Type I (segmental Injury) or Type II (global Injury).

\section{Segmental injury}

There is a positive EMG signal at laryngeal entry point but negative signal at the most proximal point of the exposed $\mathrm{RLN}^{[43]}$. The point of injury can be picked on stimulating the nerve in its entirety from the distal most point of entry proximally. The point at which the signal stops is the point of injury.

\section{Global injury}

When there is no EMG signal in the entirety of the visible portion of the nerve, it is Type II injury. However, the signal is elicited on the opposite vagal stimulation. Figure 6 gives an algorithm on the management decision in case of true LOS.

\section{OUTCOMES OF USE OF IONM Performance of the IONM}

Various series have reported a high negative predictive value (NPV) of the IONM upwards of 95\% ${ }^{[46-48]}$, making it suitable to predict that the nerve is intact. Nonetheless, IONM has a learning curve, and the operating team may encounter hurdles until a normal signal is achieved. This gives a high false LOS reducing the positive predictive value of $12 \%-88 \%$. There has been a prospective randomized controlled trial comparing conventional thyroidectomy with IONM $v s$. no IONM. Forty-one nerves at risk in patients with benign as well as malignant disease were operated on by two experienced surgeons. The findings demonstrate no RLN injuries in both arms, although the operative time for nerve identification was significantly lower in the IONM group notwithstanding the fact that total surgery time was not significantly different. Even in experienced hands, there was one false LOS $(1 / 41,2.4 \%)^{[49]}$.

Thus, from available evidence, IONM can prove beyond doubt that the nerve is normally functioning in the presence of a normal signal and one can proceed with surgery on the contralateral side. However, decision making in the case of LOS requires expert opinion in high-volume centers to negate false LOS.

\section{Outcomes in surgeries of thyroid cancer}

There is growing consensus among thyroid surgeons over deferring contralateral surgery in the event of LOS on ipsilateral side with the International Neuromonitoring Study Group endorsing this viewpoint ${ }^{[20]}$. While this would be easier in surgery of benign disease, deferring surgery of the contralateral side in thyroid cancers is a contentious issue and much debated. Needless to mention, apart from a second surgical insult, there is a question of oncological safety. There is some evidence of favorable outcomes from high-volume centers, albeit with limited numbers in support of staged surgery. The authors of one study suggested no deterioration in oncologic outcomes by deferring contralateral surgery in 35 patients of locally advanced thyroid cancers, both differentiated and medullary cancers ${ }^{[33,50]}$. 


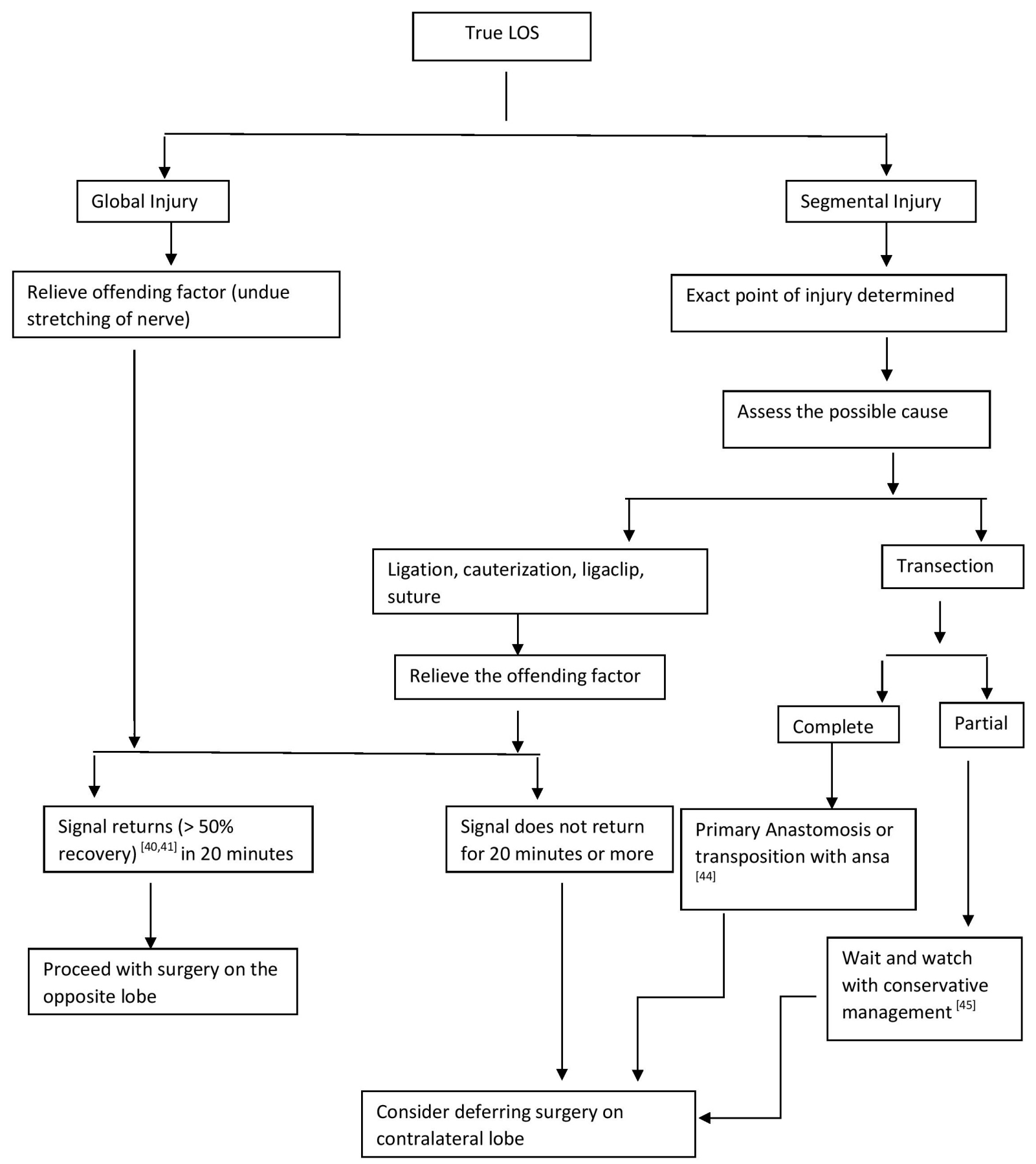

Figure 6. Algorithm for intraoperative decision-making in true LOS.

However, the authors also suggested a balanced individualized decision based on surgical fitness for second surgery, appropriate counseling of the patients, and the nature of the disease before making a decision.

\section{Deferring surgery due to LOS on ipsilateral side}

In high-volume centers, where the learning curve is surpassed and probability of false LOS is minimized, there is evidence to suggest deferring surgery on the contralateral side prevents incidence of bilateral vocal cord palsy as opposed to those performing contralateral surgery from $17 \%-28.6 \%$ to $0 \%^{[31,51,52]}$. 


\section{SPECIAL CIRCUMSTANCES}

The utility of IONM is being evaluated and appreciated in the following situations.

\section{Mapping of the RLN}

In difficult scenarios such as redo surgeries and infiltrative thyroid cancers, the RLN may be difficult to identify. In such cases, increasing the stimulation intensity to up to $2 \mathrm{~mA}$ helps to localize the nerve. After identification, further stimulation can be done by reducing the intensity to $1 \mathrm{~mA}^{[39]}$.

\section{Invasive thyroid cancers}

The American Head Neck Society, in a consensus statement, has recommended the use of IONM for all cases of invasive thyroid cancers ${ }^{[47]}$. In such cases, with a preoperative mobile vocal cord, if intraoperative signal at R1 is present proximal to the infiltrative tumor, all attempts should be made at nerve preservation ${ }^{[4]}$. Similarly, in the presence of preoperative vocal cord dysfunction, more than $30 \%$ patients demonstrate an EMG response when stimulated proximally. Preservation of such nerves results in maintenance of vocalis muscle tone, thus avoiding atrophy and resultant aspiration due to phonatory gap. Additionally, dissection of the RLN from the tumor while still preserving its integrity has been found to be easier if IONM is employed.

\section{Day care thyroidectomy}

IONM, with its high negative predictive value (>95\%), largely rules out postoperative vocal cord dysfunction in the presence of normal signal. The confirmation of nerve integrity at the end of the surgical procedure using IONM can help in making the decision of discharging a patient on the day of surgery provided all other criteria are fulfilled ${ }^{[53]}$.

\section{Paediatric thyroidectomy}

In cases of patients less than 18 years with thyroid neoplasms, IONM has been found to be useful; continuous monitoring is recommended over intermittent monitoring for prevention of complications ${ }^{[54]}$. Technical modifications to the equipment have been made to facilitate the use of IONM in children.

\section{Challenging anatomic variations}

Anatomical variations of the RLN are not infrequent, although they cannot be preempted.

(1) Extra laryngeal motor branches of the RLN are not uncommon. The RLN may branch more than $5 \mathrm{~mm}$ away from its entry into the larynx. Failure to recognize such branching may result in palsy despite an intact appearing nerve ${ }^{[55]}$. IONM helps in preventing this by identification of the motor branches, especially as these smaller branches may be mistaken for branches of the inferior thyroid artery and therefore may be ligated or cauterized.

(2) Non-RLN: As is well known, a non-recurrent laryngeal nerve is encountered in $0.6 \%-1 \%$ of all thyroidectomies, and it is almost exclusively seen on the right side ${ }^{[5]}$. Since there is no cost-effective method of identifying it preoperatively, it is best to stay aware of the entity and identify it. IONM is an effective tool in confirming a non-recurrent nerve if it exists. This is done by confirming an EMG signal from the laryngeal muscles on proximal stimulation of the vagus nerve at the level of the superior border of the thyroid cartilage in the absence of such a response distally at the level of the fourth trachea ring. 


\section{RECENT ADVANCES AND FUTURE DIRECTIONS CIONM}

CIONM, with real time monitoring, alerts the surgeon to an impending injury before actual insult to the nerve. It removes the risk to the nerve due to the temporal gap (interval between stimulations) and spatial gap (distance between the site of stimulation and the site of injury) that can happen in intermittent IONM (IIONM) ${ }^{[57]}$. Thus, the probability of permanent vocal cord palsy with CIONM is less than that of $\mathrm{IIONM}^{[46]}$. The lower risk of injury to the RLN translates into higher conversion to total thyroidectomy with the use of CIONM, as was concluded by Schneider et al. ${ }^{[4]}$ in their study of 1314 nerves at risk. The caveat is the need for extra dissection not just of the carotid sheath but also 360-degree release of the vagus for mounting and accommodating the stimulating electrode. It has been nonetheless found to be safe with respect to voice outcomes even in professional voice users ${ }^{[58]}$. Additionally, continuous albeit low-voltage stimulation of the vagus was feared to potentially increase the risk of heart blocks especially in a patient with heart disease. This has been negated by available data which suggest safety even in patients with heart blocks ${ }^{[59]}$.

\section{Monitoring of the external branch of superior laryngeal nerve}

The International Neuromonitoring Study Group has defined the role of monitoring of External Branch of Laryngeal Nerve (EBSLN) ${ }^{[60]}$. Several workers have demonstrated the feasibility and efficacy of IONM in mapping the EBSLN ${ }^{[6,62]}$. The identification of the EBSLN has been shown to be consistently better with IONM as compared to visual identification ${ }^{[63]}$. There may, however, be technical and instrumental modifications required for the proper recording of the EBSLN readings and these are still evolving.

\section{Use of IONM in remote access thyroidectomy}

IONM has been demonstrated to be useful in endoscopic and robotic thyroidectomies via all approaches ${ }^{[6,65]}$. The voice outcomes are similar to non-IONM procedures though the recovery to normal speech has been seen to be more rapid with the use of IONM. CIONM is more easily integrated in such surgeries. However, there may be difficulties involved ${ }^{[6 \sigma]}$, and the rate of artifacts and false positives may be higher than in open surgeries.

\section{CONCLUSION}

IONM is a useful adjunct in thyroid surgeries, particularly in difficult thyroid cancers, as has been highlighted in the literature ${ }^{[6,68]}$. It helps not only to identify but also to preserve and prognosticate nerve injury with advances in precision recording. The learning curve of this technique is not unsurmountable. Having achieved that, incorporation of the IONM has a bearing on critical intraoperative decision-making with regards to patient safety. Continuing innovation in IONM design as well as the fast-emerging role of CIONM will further enhance the efficacy and applicability of this tool even in remote access thyroidectomies.

\section{DECLARATIONS}

\section{Authors' contributions}

Made substantial contributions to conception and design of study, data analysis and interpretation: Priya SR, Dandekar M

Performed data acquisition, technical and material support: Garg S, Priya SR, Dandekar M

\section{Availability of data and materials}

Not applicable. 


\section{Financial support and sponsorship}

None.

\section{Conflicts of interest}

All authors declared that there are no conflicts of interest.

\section{Ethical approval and consent to participate}

Not applicable.

\section{Consent for publication}

Not applicable.

\section{Copyright}

(c) The Author(s) 2021.

\section{REFERENCES}

1. Gourin CG, Tufano RP, Forastiere AA, Koch WM, Pawlik TM, Bristow RE. Volume-based trends in thyroid surgery. Arch Otolaryngol Head Neck Surg 2010;136:1191-8. DOI PubMed

2. Misiolek M, Waler J, Namyslowski G, Kucharzewski M, Podwinski A, Czecior E. Recurrent laryngeal nerve palsy after thyroid cancer surgery: a laryngological and surgical problem. Eur Arch Otorhinolaryngol 2001;258:460-2. DOI PubMed

3. Toniato A, Boschin IM, Piotto A, et al. Complications in thyroid surgery for carcinoma: one institution's surgical experience. World $J$ Surg 2008;32:572-5. DOI PubMed

4. Lefevre JH, Tresallet C, Leenhardt L, Jublanc C, Chigot JP, Menegaux F. Reoperative surgery for thyroid disease. Langenbecks Arch Surg 2007;392:685-91. DOI PubMed

5. Pantvaidya G, Mishra A, Deshmukh A, Pai PS, D'Cruz A. Does the recurrent laryngeal nerve recover function after initial dysfunction in patients undergoing thyroidectomy? Laryngoscope Investig Otolaryngol 2018;3:249-52. DOI PubMed PMC

6. Steurer M, Passler C, Denk DM, Schneider B, Niederle B, Bigenzahn W. Advantages of recurrent laryngeal nerve identification in thyroidectomy and parathyroidectomy and the importance of preoperative and postoperative laryngoscopic examination in more than 1000 nerves at risk. Laryngoscope 2002;112:124-33. DOI PubMed

7. Baba M, Natsugoe S, Shimada M, et al. Does hoarseness of voice from recurrent nerve paralysis after esophagectomy for carcinoma influence patient quality of life? J Am Coll Surg 1999;188:231-6. DOI PubMed

8. Nouraei SAR, Allen J, Kaddour H, et al. Vocal palsy increases the risk of lower respiratory tract infection in low-risk, low-morbidity patients undergoing thyroidectomy for benign disease: a big data analysis. Clin Otolaryngol 2017;42:1259-66. DOI PubMed

9. . Equipment, recording techniques, data analysis, and stimulation. Intraoperative neurophysiological monitoring. Totowa: Humana Press; 2006. p. 299-328. DOI

10. Irkorucu O, Aziret M, Arslan E. Nerve monitoring in the hands of less experienced surgeons. Indian J Surg 2014;76:257-8. DOI PubMed PMC

11. Dionigi G, Wu CW, Kim HY, Rausei S, Boni L, Chiang FY. Severity of recurrent laryngeal nerve injuries in thyroid surgery. World J Surg 2016;40:1373-81. DOI PubMed

12. Chiang FY, Lu IC, Kuo WR, Lee KW, Chang NC, Wu CW. The mechanism of recurrent laryngeal nerve injury during thyroid surgery-the application of intraoperative neuromonitoring. Surgery 2008;143:743-9. DOI PubMed

13. Zheng S, Xu Z, Wei Y, Zeng M, He J. Effect of intraoperative neuromonitoring on recurrent laryngeal nerve palsy rates after thyroid surgery-a meta-analysis. J Formos Med Assoc 2013;112:463-72. DOI PubMed

14. Schneider R, Machens A, Randolph GW, Kamani D, Lorenz K, Dralle H. Opportunities and challenges of intermittent and continuous intraoperative neural monitoring in thyroid surgery. Gland Surg 2017;6:537-45. DOI PubMed PMC

15. Johnson RL, Warner ME, Staff NP, Warner MA. Neuropathies after surgery: anatomical considerations of pathologic mechanisms. Clin Anat 2015;28:678-82. DOI PubMed

16. Lamadé W, Béchu M, Lauzana E, et al. The weepy nerve-different sensitivity of left and right recurrent laryngeal nerves under tensile stress in a porcine model. Langenbecks Arch Surg 2016;401:983-90. DOI PubMed

17. Phelan E, Schneider R, Lorenz K, et al. Continuous vagal IONM prevents recurrent laryngeal nerve paralysis by revealing initial EMG changes of impending neuropraxic injury: a prospective, multicenter study. Laryngoscope 2014;124:1498-505. DOI PubMed

18. Schneider R, Randolph G, Dionigi G, et al. Prospective study of vocal fold function after loss of the neuromonitoring signal in thyroid surgery: The International Neural Monitoring Study Group's POLT study. Laryngoscope 2016;126:1260-6. DOI PubMed

19. Waller A. Experiments on the section of the glosso-pharyngeal and hypoglossal nerves of the frog, and observations of the alterations produced thereby in the structure of their primitive fibres. Edinb Med Surg J 1851;76:369-76. PubMed PMC

20. Schneider R, Randolph GW, Dionigi G, et al. International neural monitoring study group guideline 2018 part I: staging bilateral thyroid surgery with monitoring loss of signal. Laryngoscope 2018;128 Suppl 3:S1-17. DOI PubMed 
21. Pragacz K, Barczyński M. Evaluation of the learning curve for intraoperative neural monitoring of the recurrent laryngeal nerves in thyroid surgery. Pol Przegl Chir 2015;86:584-93. DOI PubMed

22. Dionigi G, Bacuzzi A, Boni L, Rovera F, Dionigi R. What is the learning curve for intraoperative neuromonitoring in thyroid surgery? Int J Surg 2008;6 Suppl 1:S7-12. DOI PubMed

23. Alesina PF, Hinrichs J, Meier B, Cho EY, Bolli M, Walz MK. Intraoperative neuromonitoring for surgical training in thyroid surgery: its routine use allows a safe operation instead of lack of experienced mentoring. World J Surg 2014;38:592-8. DOI PubMed

24. Prass RL, Kinney SE, Hardy RW Jr, Hahn JF, Lüders H. Acoustic (loudspeaker) facial EMG monitoring: II. Use of evoked EMG activity during acoustic neuroma resection. Otolaryngol Head Neck Surg 1987;97:541-51. DOI PubMed

25. Park JH, Hyun SJ. Intraoperative neurophysiological monitoring in spinal surgery. World J Clin Cases 2015;3:765-73. DOI PubMed $\mathrm{PMC}$

26. Thirumala PD, Mohanraj SK, Habeych M, et al. Value of free-run electromyographic monitoring of lower cranial nerves in endoscopic endonasal approach to skull base surgeries. J Neurol Surg B Skull Base 2012;73:236-44. DOI PubMed PMC

27. Shedd DP, Durham C. Electrical identification of the recurrent laryngeal nerve. I. Response of the canine larynx to electrical stimulation of the recurrent laryngeal nerve. Ann Surg 1966;163:47-50. DOI PubMed PMC

28. Dralle H, Sitges-serra A, Angelos P, et al. Intraoperative monitoring of the recurrent laryngeal nerve during thyroidectomy: a standardized approach part 2. World Journal of Endocrine Surgery 2012;4:33-40. DOI

29. Julien N, Mosnier I, Bozorg Grayeli A, Nys P, Ferrary E, Sterkers O. Intraoperative laryngeal nerve monitoring during thyroidectomy and parathyroidectomy: A prospective study. Eur Ann Otorhinolaryngol Head Neck Dis 2012;129:69-76. DOI PubMed

30. Lipton RJ, McCaffrey TV, Litchy WJ. Intraoperative electrophysiologic monitoring of laryngeal muscle during thyroid surgery. Laryngoscope 1988;98:1292-6. DOI PubMed

31. Randolph GW, Dralle H, Abdullah H, et al. International Intraoperative Monitoring Study Group. Electrophysiologic recurrent laryngeal nerve monitoring during thyroid and parathyroid surgery: international standards guideline statement. Laryngoscope 2011;121 Suppl 1:S1-16. DOI

32. NIM ${ }^{\circledR}$ 3.0 Systems: protocol and trouble Shooting guide - a comprehensive guide to nerve integrity monitoring, Medtronic Inc. Jacksonville: Johnson \& Johnson; 2012. p.17.

33. Randolph GW, Kamani D. Intraoperative neural monitoring in thyroid cancer surgery. Langenbecks Arch Surg 2014;399:199-207. DOI PubMed

34. Kim J, Roman SA. We Asked the Experts: How can one troubleshoot loss of intraoperative nerve monitoring during head and neck surgery? World J Surg 2020;44:1874-5. DOI PubMed

35. Gurleyik E, Gurleyik G. Nonrecurrent laryngeal nerve in the era of intraoperative nerve monitoring. Adv Med 2016;2016:1606029. DOI PubMed PMC

36. Pearlman RC, Isley MR, Ruben GD, et al. Intraoperative monitoring of the recurrent laryngeal nerve using acoustic, free-run, and evoked electromyography. J Clin Neurophysiol 2005;22:148-52. DOI PubMed

37. Satoh I. Evoked electromyographic test applied for recurrent laryngeal nerve paralysis. Laryngoscope 1978;88:2022-31. DOI PubMed

38. Potenza AS, Phelan EA, Cernea CR, et al. Normative intra-operative electrophysiologic waveform analysis of superior laryngeal nerve external branch and recurrent laryngeal nerve in patients undergoing thyroid surgery. World J Surg 2013;37:2336-42. DOI PubMed

39. Caragacianu D, Kamani D, Randolph GW. Intraoperative monitoring: normative range associated with normal postoperative glottic function. Laryngoscope 2013;123:3026-31. DOI PubMed

40. Sritharan N, Chase M, Kamani D, Randolph M, Randolph GW. The vagus nerve, recurrent laryngeal nerve, and external branch of the superior laryngeal nerve have unique latencies allowing for intraoperative documentation of intact neural function during thyroid surgery. Laryngoscope 2015;125:E84-9. DOI PubMed

41. Schneider R, Machens A, Lorenz K, Dralle H. Intraoperative nerve monitoring in thyroid surgery-shifting current paradigms. Gland Surg 2020;9:S120-8. DOI PubMed PMC

42. Brauckhoff K, Vik R, Sandvik L, et al. Impact of EMG changes in continuous vagal nerve monitoring in high-risk endocrine neck surgery. World J Surg 2016;40:672-80. DOI PubMed PMC

43. Wu CW, Wang MH, Chen CC, et al. Loss of signal in recurrent nerve neuromonitoring: causes and management. Gland Surg 2015;4:19-26. DOI PubMed PMC

44. Miyauchi A, Ishikawa H, Matsusaka K, Maeda M, Matsuzuka F, Hirai K, Kuma K. [Treatment of recurrent laryngeal nerve paralysis by several types of nerve suture]. Nihon Geka Gakkai Zasshi 1993;94:550-5. (in Japanese). PubMed

45. Wang LF, Lee KW, Kuo WR, Wu CW, Lu SP, Chiang FY. The efficacy of intraoperative corticosteroids in recurrent laryngeal nerve palsy after thyroid surgery. World J Surg 2006;30:299-303. DOI PubMed

46. Schneider R, Sekulla C, Machens A, Lorenz K, Nguyen Thanh P, Dralle H. Postoperative vocal fold palsy in patients undergoing thyroid surgery with continuous or intermittent nerve monitoring. Br J Surg 2015;102:1380-7. DOI PubMed

47. Barczyński M, Konturek A, Cichoń S. Randomized clinical trial of visualization versus neuromonitoring of recurrent laryngeal nerves during thyroidectomy. Br J Surg 2009;96:240-6. DOI PubMed

48. Cavicchi O, Caliceti U, Fernandez IJ, et al. The value of neurostimulation and intraoperative nerve monitoring of inferior laryngeal nerve in thyroid surgery. Otolaryngol Head Neck Surg 2009;140:866-70. DOI PubMed

49. Maneeprasopchoke P, Chongkolwatana C, Pongsapich W, Iwata AJ, Kamani D, Randolph GW. Intraoperative nerve monitoring in thyroid surgery: analysis of recurrent laryngeal nerve identification and operative time. Laryngoscope Investig Otolaryngol 2021;6:354-61. DOI PubMed PMC 
50. Salari B, Hammon RJ, Kamani D, Randolph GW. Staged surgery for advanced thyroid cancers: safety and oncologic outcomes of neural monitored surgery. Otolaryngol Head Neck Surg 2017;156:816-21. DOI PubMed

51. Goretzki PE, Schwarz K, Brinkmann J, Wirowski D, Lammers BJ. The impact of intraoperative neuromonitoring (IONM) on surgical strategy in bilateral thyroid diseases: is it worth the effort? World J Surg 2010;34:1274-84. DOI PubMed

52. Melin M, Schwarz K, Pearson MD, Lammers BJ, Goretzki PE. Postoperative vocal cord dysfunction despite normal intraoperative neuromonitoring: an unexpected complication with the risk of bilateral palsy. World J Surg 2014;38:2597-602. DOI PubMed

53. Terris DJ, Snyder S, Carneiro-Pla D, et al. American thyroid association surgical affairs committee writing task force. American thyroid association statement on outpatient thyroidectomy. Thyroid 2013;23:1193-202. DOI PubMed

54. Schneider R, Machens A, Sekulla C, Lorenz K, Weber F, Dralle H. Twenty-year experience of paediatric thyroid surgery using intraoperative nerve monitoring. Br J Surg 2018;105:996-1005. DOI PubMed

55. Hermann M, Hellebart C, Freissmuth M. Neuromonitoring in thyroid surgery: prospective evaluation of intraoperative electrophysiological responses for the prediction of recurrent laryngeal nerve injury. Ann Surg 2004;240:9-17. DOI PubMed PMC

56. Kamani D, Potenza AS, Cernea CR, Kamani YV, Randolph GW. The nonrecurrent laryngeal nerve: anatomic and electrophysiologic algorithm for reliable identification. Laryngoscope 2015;125:503-8. DOI PubMed

57. Dionigi G, Donatini G, Boni L, et al. Continuous monitoring of the recurrent laryngeal nerve in thyroid surgery: a critical appraisal. International Journal of Surgery 2013;11:S44-6. DOI PubMed

58. Çekiç E, Dönmez T, Sürmelioğlu Ö, Ferahman S, Hatipoğlu E, Kocakuşak A. Effect of intraoperative neuromonitoring on voice quality in total thyroidectomy. Haseki 2018;56:118-24. DOI

59. Lamadé W, Ulmer C, Seimer A, et al. A new system for continuous recurrent laryngeal nerve monitoring. Minim Invasive Ther Allied Technol 2007;16:149-54. DOI PubMed

60. Barczyński M, Randolph GW, Cernea CR, et al. International neural monitoring study group. External branch of the superior laryngeal nerve monitoring during thyroid and parathyroid surgery: international neural monitoring study group standards guideline statement. Laryngoscope 2013;123 Suppl 4:S1-14. DOI PubMed

61. Sun H, Dionigi G. Monitoring the external branch of the superior laryngeal nerve in thyroid surgery. Ann Thyroid 2018;3:9-9. DOI PubMed

62. Uludag M, Aygun N, Kartal K, et al. Contribution of intraoperative neural monitoring to preservation of the external branch of the superior laryngeal nerve: a randomized prospective clinical trial. Langenbecks Arch Surg 2017;402:965-76. DOI PubMed

63. Glover AR, Norlén O, Gundara JS, Morris M, Sidhu SB. Use of the nerve integrity monitor during thyroid surgery aids identification of the external branch of the superior laryngeal nerve. Ann Surg Oncol 2015;22:1768-73. DOI PubMed

64. Lang BH, Wong KP. Feasibility on the use of intraoperative vagal nerve stimulation in gasless, transaxillary endoscopic, and roboticassisted thyroidectomy. J Laparoendosc Adv Surg Tech A 2011;21:911-7. DOI PubMed

65. Kandil E, Winters R, Aslam R, Friedlander P, Bellows C. Transaxillary gasless robotic thyroid surgery with nerve monitoring: initial two experince in a North American center. Minim Invasive Ther Allied Technol 2012;21:90-5. DOI PubMed

66. Zhao Y, Li C, Zhang D, et al. Continuous neural monitoring in endoscopic thyroidectomy: feasibility experimental study for transcutaneous vagal nerve stimulation. J Laparoendosc Adv Surg Tech A 2020;30:1095-101. DOI PubMed

67. Calò PG, Pisano G, Medas F, et al. Identification alone versus intraoperative neuromonitoring of the recurrent laryngeal nerve during thyroid surgery: experience of 2034 consecutive patients. J Otolaryngol Head Neck Surg 2014;43:16. DOI PubMed PMC

68. Calò PG, Medas F, Erdas E, et al. Role of intraoperative neuromonitoring of recurrent laryngeal nerves in the outcomes of surgery for thyroid cancer. Int J Surg 2014;12 Suppl 1:S213-7. DOI PubMed 